\title{
Generalization of above/below, right/left effects to compass directions and natural stimuli
}

\author{
RUTH H. MAKI, WILLIAM S. MAKI, JR., and LINDA G. MARSH \\ North Dakota State University, Fargo, North Dakota 58102
}

\begin{abstract}
In two experiments subjects decided whether a sentence correctly described the locations of two states of the United States or correctly described the locations of two symbols presented above it. Sentences involved either spatial relations (right, left, above, and below) or compass relations (east, west, north, and south). For vertically aligned symbols, both "above" and "north" were responded to faster than "below" and "south." For vertically aligned states, however, this effect was present only for true statements. For horizontally aligned stimuli, "right" and "east" were faster than "left" and "west" with the perceptually available symbols but not with memorized states. These findings were discussed in terms of the Clark and Chase (1972) model of picture-sentence verification processes.
\end{abstract}

Clark and Chase (1972) have shown that people generally prefer to encode the positions of two vertically arranged objects with the term "above" rather than "below." When pictures of two objects were presented and subjects determined whether a sentence correctly described the locations of the objects, use of the word "above" in the sentence resulted in faster reaction times (RTs) than did use of the word "below." Clark (1973) suggested that the upward direction is generally positive, since humans use ground level as a reference point. Olson and Laxar (1973) extended this analysis to the terms "right" and "left." For right-handed subjects, the word "right" yielded faster RTs than did "left." Olson and Laxar concluded that "right" is conceptually simpler than "left."

Maki, Maki, and Marsh (in press) used a task similar to that of Clark and Chase (1972) to compare the speed of locational judgments of vertically and horizontally aligned stimuli. They found that judgments within the vertical dimension were faster than judgments within the horizontal dimension for two types of stimuli: locations of states of the United States, which were assumed to be in long-term memory, and arbitrary symbols, which were present during the judgment task. Maki et al. also used both compass (north, south, east, west) and spatial (above, below, right, left) locatives. The purpose of the present paper is to compare the RTs obtained by Maki et al. for above (north) vs. below (south) and right (east) vs. left (west) so that it can be determined whether the effects found by Clark and Chase (1972) and by Olson and Laxar (1973) extend to the compass locatives and to natural stimuli assumed to be stored in long-term memory.

\section{METHOD}

\section{Material and Design}

Experiment 1 involved state stimuli and Experiment 2 involved symbol stimuli. For the state stimuli, sentences were constructed from 32 pairs of states. In each of 16 "east-west" pairs, the two states were of approximately the same latitude; in each of the other 16 "north-south" pairs, the states were of approximately the same longitude. On the average, "east-west" and "north-south" states were about equally far apart. Members of state pairs were used equally often as subjects and as predicates of sentences of the form "(state) is (locative) (state)." For east-west pairs, locatives were "east of," "west of," "right of," and "left of." For north-south pairs, locatives were "north of," "south of," "above," and "below." Therefore, one-half of the sentences involving each pair of states were true and onehalf were false.

In Experiment 2, using artificial stimuli, names of two symbols were substituted for names of states, and the symbols appeared directly above the stimulus sentences. Otherwise, the design was the same as with state stimuli. The symbols were a typed asterisk and a lowercase letter "o." The asterisk (referred to as "star") was above or below the letter (referred to as "circle"), or the star was left or right of the circle. The sentences were of the form "(symbol) is (locative) (symbol)." Both compass and spatial locatives were used. Symbol names appeared equally frequently as subjects and objects in sentences.

Within each experiment, a between-subjects variable was the order in which compass and spatial locatives were presented. For one half of the subjects, compass locatives preceded spatial locatives; this ordering was reversed for the other half of the subjects. While stimuli from both the vertical and horizontal dimensions were presented to all subjects, each dimension was considered as a separate design. Within each dimension, three within-subjects variables were manipulated. These were direction (upward vs. downward or right vs. left), truth, and type of locative (compass vs. spatial). There were 16 sentences in each of the four cells of the design defined by direction and truth, so that there were a total of 64 sentences referring to the horizontal dimension and 64 sentences referring to the vertical 
dimension. Except for specific locatives, the same 128 sentences were repeated in both the spatial and compass conditions.

Each subject served in four 20 -min sessions, with three trays of 32 slides presented during each session. The first tray was regarded as warm-up, and the last two trays provided the data reported below. Tray orders were arranged so that data collected during the last two trays of the two sessions spent on either compass or spatial locatives were based on all four trays. Across subjects, each tray was used as warm-up equally often. Spatial locatives were presented during two of the sessions and compass locatives were presented during the other two.

\section{Apparatus}

Each sentence was typed and placed in slide mounts (for $35-\mathrm{mm}$ film). The sentence was typed with the subject state or symbol occupying the top row of print, the object state or symbol occupying the bottom row of print, and the verb and locative (e.g., is north of) occupying the middle row. In Experiment 2 the two symbols were typed above the sentences. Insofar as possible, the stimuli were centered both vertically and horizontally on the slide. Each tray of slides contained 32 sentences (4 randomized blocks of 8 ). The sentences were presented to the subject on a rear-projection screen via Kodak Carousel projectors to which Lafayette tachistoscopic shutters had been attached. Timing was controlled by an LVB logic box and RTs were measured to the nearest millisecond with a Hunter Klockounter. The subject was seated about $45 \mathrm{~cm}$ in front of the screen, and stimuli on the screen occupied a space of about $21 \times 15 \mathrm{~cm}$. Two microswitches, mounted about $22 \mathrm{~cm}$ apart on a small console, were used to detect responses.

\section{Procedure}

Subjects were instructed to read each statement and decide whether it was true or false based on their knowledge of United States geography or on the location of the two symbols. True statements were indicated by pressing a switch with the index finger of the preferred hand; false statements were indicated by pressing the other switch with the index finger of the other hand. Each trial began with a warning signal (a cross composed of typed lowercase Xs) for $.5 \mathrm{sec}$, followed immediately by the sentence. The subject's response terminated display of the sentence and stopped the Klockounter. A short break was provided after every 32 slides, during which slide trays were changed.

\section{Subjects}

Twelve subjects served in Experiment 1 and 12 different subjects served in Experiment 2. All were volunteers from introductory psychology classes at North Dakota State University and received bonus points toward their grade as compensation for their participation.

\section{RESULTS AND DISCUSSION}

In these analyses, mean RTs were based on up to 16 observations per cell. Data were classified by truth, type of locative (spatial vs. compass), and direction. For analysis of sentences containing vertically oriented stimuli, RTs for sentences containing the directional words "above" and "north" were compared with those containing the words "below" and "south." For sentences containing horizontally oriented stimuli, the directional words "right" and "east" were compared with "left" and "west." Separate analyses of variance were performed on sentences reflecting horizontal and on those reflecting vertical relations.

\section{Vertical Stimuli}

Mean RTs for vertically aligned states and symbols are summarized in Table 1. In Experiment 1, with state stimuli, sentences containing the words "above" and "north" were verified more rapidly than sentences containing the words "below" and "south" $[F(1,10)=$ $19.24, \mathrm{p}<.05$ ] (the significance level to be adopted throughout this paper). True sentences were responded to faster than false sentences $[F(1,10)=8.21]$. These factors interactively determined $\mathrm{RT}[\mathrm{F}(1,10)=9.65]$; smaller RTs for above-north as compared to belowsouth sentences were observed if the statement was true $(2,219$ vs. $2,472 \mathrm{msec})[\mathrm{F}(1,10)=16.94]$, but not if the statement was false $(2,495$ vs. $2,528 \mathrm{msec})$ $[F(1,10)=1.26]$. There was neither an effect of locative set $[F(1,10)=2.10]$ nor an interaction of Locative Set by Direction $(F<1)$. The error pattern was essentially the same as the pattern of RTs, with errors ranging from $2.6 \%$ with the word "above" to $12.0 \%$ with "below."

In Experiment 2 with vertically oriented symbols, spatial locatives (above and below) produced shorter RTs than compass locatives (north and south) $[F(1,10)=6.83]$, but locative set did not interact with direction $(\mathrm{F}<1)$. The words "north" and "above" produced faster responses $(1,453 \mathrm{msec})$ than the words "south" and "below" $(1,518 \mathrm{msec})[\mathrm{F}(1,10)=8.63]$, and true sentences were responded to more quickly than were false sentences $[F(1,10)=58.38]$. However, truth and direction did not interactively determine RT $[F(1,10)=2.14]$. Again the pattern of errors paralleled the pattern of RTs and ranged from $2.1 \%$ errors with the word "above" to $9.4 \%$ errors with the word "south."

Truth and direction interacted with memorized state stimuli, but they were additive with perceptually available symbol stimuli. The pattern of results with state stimuli was much like what Clark and Chase (1972) found when the picture was encoded before the sentence, while the pattern of results with the symbol stimuli was much like what they found when the sentence was encoded before the picture. Likewise, Just and Carpenter (1975), who had subjects make locational discriminations from letter arrays which were either memorized or present as part of the display, found that truth modulated reactions to sentences containing "above" vs.

Table 1

Mean Reaction Times in Milliseconds for Vertically Aligned Stimuli

\begin{tabular}{|c|c|c|c|c|c|}
\hline \multirow[b]{2}{*}{ Truth } & \multirow[b]{2}{*}{$\begin{array}{l}\text { Type of } \\
\text { Locative }\end{array}$} & \multicolumn{2}{|c|}{$\begin{array}{l}\text { Experiment } 1 \\
\text { (States) }\end{array}$} & \multicolumn{2}{|c|}{$\begin{array}{c}\text { Experiment } 2 \\
\text { (Symbols) }\end{array}$} \\
\hline & & $\begin{array}{l}\text { Above } \\
\text { (North) }\end{array}$ & $\begin{array}{l}\text { Below } \\
\text { (South) }\end{array}$ & $\begin{array}{l}\text { Above } \\
\text { (North) }\end{array}$ & $\begin{array}{l}\text { Below } \\
\text { (South) }\end{array}$ \\
\hline True & $\begin{array}{l}\text { Spatial } \\
\text { Compass }\end{array}$ & $\begin{array}{l}2153 \\
2285\end{array}$ & $\begin{array}{l}2417 \\
2527\end{array}$ & $\begin{array}{l}1324 \\
1445\end{array}$ & $\begin{array}{l}1359 \\
1497\end{array}$ \\
\hline False & $\begin{array}{l}\text { Spatial } \\
\text { Compass }\end{array}$ & $\begin{array}{l}2462 \\
2528\end{array}$ & $\begin{array}{l}2469 \\
2586\end{array}$ & $\begin{array}{l}1464 \\
1578\end{array}$ & $\begin{array}{l}1507 \\
1711\end{array}$ \\
\hline
\end{tabular}


"below" when responses were based on a letter array stored in memory, but truth did not interact with direction when the letter array was present during the response. Apparently, memorized information about locations along the vertical continuum tends to be organized similarly across a wide range of materials, since such diverse materials as memorized letter arrays and geographical locations yielded the same pattern of results.

The present data can be explained in terms of the model proposed by Clark and Chase (1972). When the picture is encoded before the sentence, as was the case with the memorized state stimuli, they assumed that there is a preference for encoding pictorial information in terms of "above." Therefore, a true statement of the form "X above $Y$ " matches the encoding of the picture; any other statement requires transformation in order for the pictorial encoding and the sentence to match. Therefore, true, above sentences should yield faster RTs than any of the other three types (false, above; true and false, below). The present data fit this model nicely if one assumes that states are encoded in memory with a north-to-south organization.

Clark and Chase (1972) found that truth and direction had additive effects when they instructed subjects to attend to the sentence before the picture. They assumed that the encoding of the picture was matched to the words used in the sentence, and encodings employing the concept underlying "above" were easier than encodings employing the concept underlying "below." While no specific instructions were given concerning order of attention to the picture or sentence in the present experiment with symbols, it appears that subjects first attended to the sentence and then to the symbols. Following the interpretation of Clark and Chase, the words representing the concept of upward (i.e., both above and north) were easier to process than words representing the concept of downward (i.e., below and south).

In both the experiment with states and the experiment with symbols, the compass terms "north" and "south" resulted in performances very similar to those resulting from the spatial terms "above" and "below." Just as "above" seems to be a basically positive term, so does "north." In his linguistic analysis of locatives, Leech (1970) claimed that " $X$ is north of $Y$ " is cognitively synonymous with " $Y$ is south of $X$." However, our results have shown that the expression using the word "north" is cognitively "simpler" than the expression using the word "south."

\section{Horizontal Stimuli}

Mean RTs for the horizontally oriented state and symbol stimuli are presented in Table 2. In Experiment 1 with state stimuli, three left-handed subjects were excluded, leaving nine subjects. True statements were reacted to more quickly than false statements $[F(1,7)=$
Table 2

Mean Reaction Times in Milliseconds for Horizontally Aligned Stimuli

\begin{tabular}{|c|c|c|c|c|c|}
\hline \multirow[b]{2}{*}{ Truth } & \multirow[b]{2}{*}{$\begin{array}{l}\text { Type of } \\
\text { Locative }\end{array}$} & \multicolumn{2}{|c|}{$\begin{array}{l}\text { Experiment } 1 \\
\text { (States) }\end{array}$} & \multicolumn{2}{|c|}{$\begin{array}{c}\text { Experiment } 2 \\
\text { (Symbols) }\end{array}$} \\
\hline & & $\begin{array}{l}\text { Right } \\
\text { (East) }\end{array}$ & $\begin{array}{c}\text { Left } \\
\text { (West) }\end{array}$ & $\begin{array}{l}\text { Right } \\
\text { (East) }\end{array}$ & $\begin{array}{l}\text { Left } \\
\text { (West) }\end{array}$ \\
\hline True & $\begin{array}{l}\text { Spatial } \\
\text { Compass }\end{array}$ & $\begin{array}{l}3140 \\
3167\end{array}$ & $\begin{array}{l}3211 \\
2967\end{array}$ & $\begin{array}{l}1438 \\
1635\end{array}$ & $\begin{array}{l}1613 \\
1649\end{array}$ \\
\hline False & $\begin{array}{l}\text { Spatial } \\
\text { Compass }\end{array}$ & $\begin{array}{l}3526 \\
3355\end{array}$ & $\begin{array}{l}3503 \\
3198\end{array}$ & $\begin{array}{l}1628 \\
1809\end{array}$ & $\begin{array}{l}1780 \\
1954\end{array}$ \\
\hline
\end{tabular}

6.06]. RTs to left-west sentences were not significantly different from RTs to right-east sentences $[F(1,7)=$ 1.62] . In contrast to predictions derived from Olson and Laxar's (1973) findings, left-west sentences were responded to slightly faster $(3,220 \mathrm{msec})$ than right-east sentences $(3,297 \mathrm{msec})$. Locative set was not significant and it did not interact with direction $\left[F_{s}(1,7)=1.62\right.$, and 2.37, respectively].

In Experiment 2 with symbols, two left-handed subjects were excluded from the analysis of horizontally oriented symbols. Analysis of RTs indicated that the words "right" and "east" produced shorter RTs $(1,628 \mathrm{msec})$ than the words "left" and "west" $(1,749 \mathrm{msec}) \quad[\mathrm{F}(1,8)=7.56]$. True sentences were responded to more quickly than false sentences $[F(1,8)=52.75]$. Neither locative set nor the Locative Set by Direction interaction was significant $\left[F_{s}(1,8)=\right.$ 2.82 and 1.13 , respectively]. The error pattern paralleled the RT data with a range of $1.2 \%$ errors with the word "right" to $13.8 \%$ errors with "left."

With symbols as stimuli, the findings of Olson and Laxar (1973) were generally replicated, that is, the word "right" was responded to more quickly than the word "left." A similar pattern also emerged with the terms "east" and "west." In contrast to these results with perceptual stimuli is the finding in Experiment 1 with memorized stimuli that right-east judgments were not faster than left-west judgments. Just and Carpenter (1975) also failed to find that "right" judgments were faster than "left" with memorized letter arrays; indeed, for true sentences the word "left" was responded to faster than "right" in their study. However, when letter arrays were presented visually (Just \& Carpenter, 1975, Experiment 2), "right" statements were responded to faster than "left." Just and Carpenter suggested one reason why their memorized stimuli differed from perceptual stimuli. They hypothesized that a horizontal row of letters is encoded from left to right, consistently with reading habits. There is an advantage whenever the subject of a sentence is on the left of the memorized array, as in true "left" sentences and false "right" sentences. This advantage accrues because items on the left in memory are more available to subjects, but with perceptual stimuli, both items are equally available and 
the ease of processing the words "right" and "left" solely determines RT. With state stimuli in memory, such a reading-habit analysis would not apply, and indeed state stimuli showed a different pattern from Just and Carpenter's memorized letter arrays. States may be relatively unorganized with respect to the horizontal dimension. With perceptual stimuli, then, the term "right" appears to be responded to faster than the term "left," but with memorized stimuli the organization of the materials seems to be the important factor in determining the speed of reactions based on the terms "right" and "left."

There was also a different pattern with perceptual and memorized stimuli in the vertical dimension. "Above" was faster than "below" for both true and false sentences when stimuli were present during the choice period. However, when stimuli had been memorized, "above" sentences were faster than "below" sentences, but only if they were true. The model by Clark and Chase (1972) suggested that this was because the stimuli are organized with respect to north, while they are relatively unorganized in the east-west dimension. Such organizational factors seem to be unim- portant with perceptual stimuli; "above-north" was easier than "below-south" and "right-east" was easier than "left-west."

\section{REFERENCES}

Clark, H. H. Space, time, semantics, and the child. In T. E. Moore (Ed.), Cognitive development and the acquisition of language. New York: Academic Press, 1973.

Clark, H. H., \& Chase, W. G. On the process of comparing sentences against pictures. Cognitive Psychology, 1972, 3, 472-517.

Just, M. A., \& Carpenter, P. A. The semantics of locative information in pictures and mental images. British Journal of Psychology, 1975, 66, 427-441.

LEECH, G. Towards a semantic description of English. Bloomington, Ind: Indiana University Press, 1970.

Maki, R. H., MaKI, W. S., JR., \& Marsh, L. G. Processing locational and orientational information. Memory \& Cognition, in press.

Olson, G. M., \& Laxar, K. Asymmetries in processing the terms "right" and "left." Journal of Experimental Psychology, 1973, 100, 284-290.

(Received for publication June 13, 1977.) 